\title{
Clinical variants of myocardial involvement in COVID-19-positive patients: a cumulative experience of 2020
}

\author{
Maya Guglin $^{1}$ (1) $\cdot$ Kareem Ballut $^{1} \cdot$ Onyedika Ilonze ${ }^{1} \cdot$ Mark Jones $^{1} \cdot$ Roopa Rao $^{1}$
}

Accepted: 9 June 2021 / Published online: 2 July 2021

() The Author(s), under exclusive licence to Springer Science+Business Media, LLC, part of Springer Nature 2021

\begin{abstract}
Myocardial injury, diagnosed by troponin elevation, is common in COVID-19 patients, but cardiac involvement with clinical manifestations occurs less frequently. We analyzed the literature on COVID-19 (2020) and systematically reviewed the cases where individual patient data were presented. We searched PubMed and Google Scholar for "COVID," "COVID-19," and "coronavirus" in combination with "myocarditis," "heart failure," "takotsubo," "cardiomyopathy," and "cardiogenic shock." We identified 90 cases of COVID-19 with myocardial involvement, mean age $52.9 \pm 18.3$ years, $54.5 \%$ males. Of them, 55 survived (61.1\%), 20 died (22.2\%), and in 15 (16.7\%) the outcome was unknown at the time of publication. Among patients with known outcome, mortality was $26 \%$. The nadir LVEF was $31.7 \pm 13.1 \%$ and recovered to $50.1 \pm 16.0 \%$. Pericardial effusion was a common finding, reported in 21 (23.3\%) of patients, including moderate size effusion in $8.9 \%$ and large in $7.8 \%$. The effusion caused tamponade in $11(12.2 \%)$ of patients. Out of 83 patients who experienced a decrease in LVEF, 30 could be classified as takotsubo syndrome. The takotsubo patients were older than those with myocarditis, and with relatively high proportion of males. About one third of the cases was complicated by cardiogenic shock. Myocardial involvement in COVID-19 patients most often presents as a new, rapid decrease in LVEF, although normal LVEF or takotsubo-like wall motion pattern does not rule out myocarditis. Moderate and large pericardial effusion is common, and cardiac tamponade occurs in $12.2 \%$ of patients. Cardiogenic shock develops in one third of the patients. Mortality appears to be high at $26 \%$.
\end{abstract}

Keywords COVID-19 Coronavirus $\cdot$ Myocarditis $\cdot$ Takotsubo $\cdot$ Heart failure $\cdot$ Aortic pulsatility index $\cdot$ Mortality

\section{Introduction}

COVID-19, a novel coronavirus infection, which became a pandemic in early 2020, had a profound effect on all spheres of human life and became a tremendous medical and public health challenge. COVID-19 is a single-stranded ribonuclear acid (RNA) highly contagious virus which primarily attacks respiratory system but can also cause multiple effects on other systems and organs.

While it is obvious that the respiratory system is most consistently affected, cardiovascular effects are significant. On the one hand, patients with underlying cardiovascular diseases, such as hypertension, coronary artery disease, heart failure (HF), or diabetes are at increased risk for complications and mortality, which may be up to tenfold

Maya Guglin

mguglin@gmail.com

1 Krannert Institute of Cardiology, Indiana University, 1801 Senate Blvd Suite 2000, IN 46202 Indianapolis, USA higher than in patients without cardiac conditions [1]. On the other hand, COVID-19 is often accompanied by myocardial injury, which may be caused by a direct viral involvement of the myocardium or by a hyperimmune response to the virus. Myocardial injury-defined as elevation in troponin levels to 3 times higher of normal serum concentrations or above their 99th percentile upper reference limit-has been reported in $20-30 \%$ of patients hospitalized due to COVID19 [2]. The final result may also be a product of the both processes when direct viral entry and replication in myocardium may enhance the susceptibility to myocardial injury, which then leads to myocarditis as a part of inflammatory response. Right ventricular dysfunction can also result from the strain caused by increased pulmonary vascular resistance and the workload on the right heart [3]. HF in COVID-19 patients is usually acute and represents de novo cases rather than exacerbation of previously diagnosed condition. Patients developing HF had significantly higher mortality $(46.8 \%$ vs. $19.7 \% ; P<0.001)[4]$. 
Although myocardial injury, diagnosed primarily by troponin elevation, is common in COVID-19-positive patients, clinical manifestations of cardiac involvement occur less frequently. The goal of the present review is to summarize the collective experience of 2020 with patients who present with clinical manifestations of myocardial involvement in the course of COVID-19 disease.

\section{Methods}

\section{Study design}

This study was a systematic review of the literature conducted following PRISMA guidelines [5] to retrieve publications containing data regarding clinical presentations, course, and outcomes of COVID-19-positive patients with myocardial involvement.

Registration of a review protocol was unnecessary because data contained in published literature was used to conduct this study.

\section{Eligibility criteria}

The publications included were full-length manuscripts retrieved with our search that contained data on one or more patients 18 years old or older, with a positive test for COVID-19, and with myocardial involvement diagnosed by one or more of the following characteristics: (1) new systolic dysfunction reported as a decrease in left ventricular ejection fraction (LVEF), (2) pericardial effusion in combination with elevated troponin and B-type natriuretic peptides (BNP or NT-proBNP), (3) myocarditis on magnetic resonance imaging with preserved LVEF.

Publications were excluded if these were written in languages other than English, contained pediatric population data (patients younger than 18 years old), or had insufficient data on individual patients.

\section{Search method}

Following PRISMA guidelines [5], a systematic search of the literature was conducted in December 2020 using PubMed, Google Scholar, and EMBASE. The keywords "COVID," "COVID-19," and "coronavirus" in combination with "myocarditis," "heart failure," "cardiomyopathy," "takotsubo," and "cardiogenic shock." In relevant papers, the list of references was manually searched as well.

The search was limited to the articles published in English in 2020 (January 1 to December 31). All the identified publications were screened to excluded duplicates by comparing titles, authors, and digital object identifiers. After removing duplicates, all the remaining publications were screened for exclusion criteria by reading titles and abstracts. After removing publications that met exclusion criteria, the reminding publications were further screened for inclusion and exclusion criteria by reading the full-text publications. The list of references for each relevant publication was manually examined. Through this searched method, the publications to include in the analysis were identified (Fig. 1).

\section{Data extraction process}

The included publications were analyzed in a qualitative manner for authors' names, date of publication, medical center where they were treated, country, and the timeline of the events. These publications were used to identify our subjects of interest. Once identified, subjects were labeled, and their data extracted. These data were used to perform quantitative analyses of comorbidities, biomarkers, symptoms on presentation, dynamical changes of LVEF, wall motion abnormalities, presence of cardiogenic shock, treatment modalities, and outcomes (survival to discharge).

\section{Results}

\section{Literature search}

The search identified 657 publications. After removing duplicates and screening for exclusion and inclusion criteria, 68 publications were included in the analysis (Fig. 1).

\section{Patient characteristics}

We identified 90 cases of COVID-19 with myocardial involvement with data available on individual patients, mean age was $52.9 \pm 18.3$ years, and $54.5 \%$ were males. The reports came from 17 countries, including 42 (46.7\%) from North America, 34 (37.8\%) from Europe, 12 (13.3\%) from Asia, and 2 (2.2\%) from South America. Myocardial involvement was diagnosed by (1) new systolic dysfunction $(92 \%)$, (2) pericardial effusion with elevated troponin and B-type natriuretic peptides with normal LVEF (1\%), and (3) myocarditis on magnetic resonance imaging with preserved LVEF (6.8\%). Of them, 55 survived (61.1\%), 20 died $(22.2 \%)$, and in $15(16.7 \%)$, the outcome was either unknown at the time of publication or not reported.

In the whole cohort, cardiac risk factors such as diabetes, hypertension, or hyperlipidemia were common. Diabetes was reported in $24.4 \%$, hypertension in $35.6 \%$, and other risk factors in $26.7 \%$. These conditions were frequently combined in the same patients.

In clinical presentation, fever (60\%) and dyspnea (58.9\%) were the most prevalent symptoms, followed by cough (44.4\%), general weakness/fatigue/malaise (43.3\%), chest 


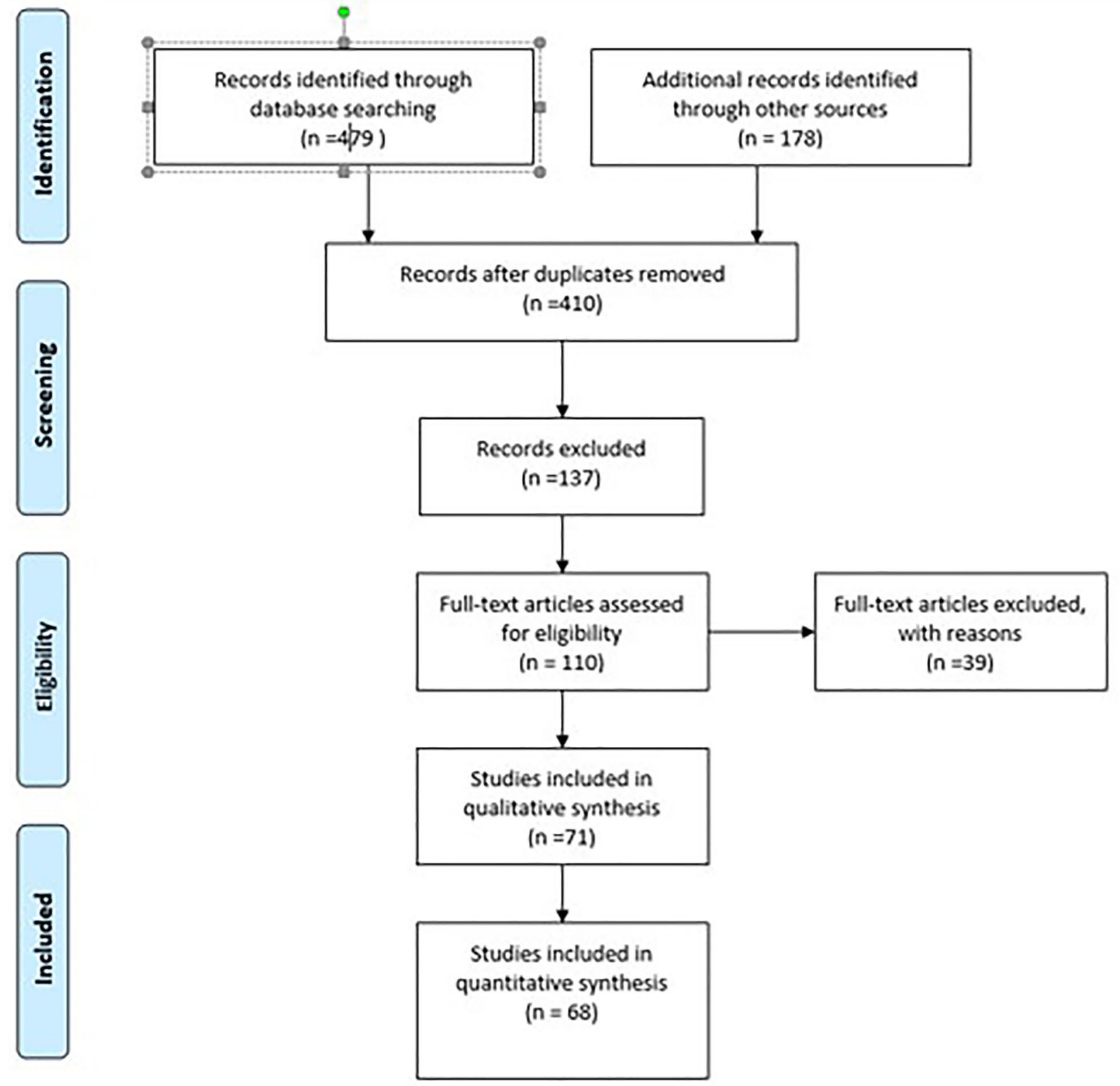

Fig. 1 Study selection flowchart

pain $(21.1 \%)$, and abdominal symptoms (nausea, vomiting, diarrhea) (14.4\%). Upper respiratory symptoms were reported in a minority of patients $(1.1 \%)$. Bilateral pulmonary infiltrates on chest X-ray (CXR) were present in $64.4 \%$ of patients, absent in $14.4 \%$, and not reported in the rest.

In terms of elevated biomarkers or inflammatory factors, troponin was elevated in $80 \%$, within normal limits in $6.7 \%$, and not reported in $13.3 \%$. The corresponding percentages of elevated, normal, and not reported values for other tests were as follows: B-type natriuretic peptide or NT-pro-BNP, $57.8 \%, 3.3 \%$, 41.9\% ; ferritin, 36.7\%, 6.7\%, 56.6\%; C-reactive protein (C-RP), $61.1 \%, 2.0 \%, 369 \%$; and interleukin-6 (IL-6), $21.1 \%, 0 \%, 78.9 \%$, respectively.
The quantitative analysis of the levels of biomarkers was not feasible because of a wide variety of assays and reference values utilized by different centers.

In almost all patients, there were some abnormalities on the electrocardiogram (ECG), but they were mostly nonspecific. Prolonged QT interval was observed in $6.7 \%$ of cases, and ST segment elevation was seen in $30.0 \%$ of patients.

Pericardial effusion was a relatively common finding, reported in $21(23.3 \%)$ of patients, including moderate size effusion in $8.9 \%$ and large in $7.8 \%$. The effusion caused tamponade in $11(12.2 \%)$ of patients.

Many patients required vasopressors and/or inotropes $(46.7 \%)$, and $11(12.2 \%)$ were placed on venoarterial 
extracorporeal membrane oxygenation (VA ECMO). In terms on anti-inflammatory, antiviral therapies, and immunomodulators, hydroxychloroquine was used most (36.7\%), steroids were given to $28.9 \%$, tocilizumab to $12.2 \%$, and remdesevir, convalescent plasma, intravenous immunoglobulin were utilized in a very small number of cases. The comparison between males and females is presented in Table 1.
Among 75 patients with known outcome, 55 survived and 20 died (mortality was $26.7 \%)$. Except for older age $(65.1 \pm 13.8$ vs $49.8 \pm 18.4, p=0.0018$ ), nonsurvivors were not different from survivors by the prevalence of cardiac risk factors or symptoms.

Comparison of survivors vs nonsurvivors is shown in Table 2.

Listed as causes of death were cardiogenic shock, septic shock, cardiac arrest, multiorgan failure, and respiratory failure.
Table 1 Patient characteristics: males vs females

\begin{tabular}{|c|c|c|c|c|c|c|}
\hline & M & & $\mathrm{F}$ & & Total & \\
\hline Total & 49 & $100.0 \%$ & 41 & $100.0 \%$ & 90 & $100.0 \%$ \\
\hline \multicolumn{7}{|l|}{ Symptoms } \\
\hline Fever & 32 & $65.3 \%$ & 22 & $53.7 \%$ & 54 & $60.0 \%$ \\
\hline General & 18 & $36.7 \%$ & 21 & $51.2 \%$ & 39 & $43.3 \%$ \\
\hline Dyspnea & 34 & $69.4 \%$ & 19 & $46.3 \%$ & 53 & $58.9 \%$ \\
\hline Cough & 25 & $51.0 \%$ & 15 & $36.6 \%$ & 40 & $44.4 \%$ \\
\hline Abdominal pain & 8 & $16.3 \%$ & 5 & $12.2 \%$ & 13 & $14.4 \%$ \\
\hline Chest pain & 13 & $26.5 \%$ & 6 & $14.6 \%$ & 19 & $21.1 \%$ \\
\hline Upper respiratory & 0 & $0.0 \%$ & 1 & $2.4 \%$ & 1 & $1.1 \%$ \\
\hline Lung infiltrates & 31 & $63.3 \%$ & 27 & $65.9 \%$ & 58 & $64.4 \%$ \\
\hline \multicolumn{7}{|l|}{ Elevated biomarkers } \\
\hline Troponin & 39 & $79.6 \%$ & 33 & $80.5 \%$ & 72 & $80.0 \%$ \\
\hline Natriuretic peptides & 28 & $57.1 \%$ & 24 & $58.5 \%$ & 52 & $57.8 \%$ \\
\hline QT & 3 & $6.1 \%$ & 3 & $7.3 \%$ & 6 & $6.7 \%$ \\
\hline ST elevation & 13 & $26.5 \%$ & 14 & $34.1 \%$ & 27 & $30.0 \%$ \\
\hline \multicolumn{7}{|l|}{ Cardiac risk factors } \\
\hline Diabetes & 12 & $24.5 \%$ & 10 & $24.4 \%$ & 22 & $24.4 \%$ \\
\hline Hypertension & 17 & $34.7 \%$ & 15 & $36.6 \%$ & 32 & $35.6 \%$ \\
\hline \multicolumn{7}{|l|}{ Echocardiographic findings } \\
\hline Left ventricular ejection fraction, $\%$ & $33.6 \pm 13.1$ & & $31.9 \pm 14.0$ & & & \\
\hline Pericardial effusion & 5 & $10.2 \%$ & 16 & $39.0 \%$ & 21 & $23.3 \%$ \\
\hline - Moderate & 0 & $0.0 \%$ & 8 & $19.5 \%$ & 8 & $8.9 \%$ \\
\hline - Large & 3 & $6.1 \%$ & 4 & $9.8 \%$ & 7 & $7.8 \%$ \\
\hline \multirow[t]{2}{*}{ - Tamponade } & 3 & $6.1 \%$ & 8 & $19.5 \%$ & 11 & $12.2 \%$ \\
\hline & 0 & $0.0 \%$ & 0 & $0.0 \%$ & 0 & $0.0 \%$ \\
\hline Hydroxychloroquine & 17 & $34.7 \%$ & 16 & $39.0 \%$ & 33 & $36.7 \%$ \\
\hline Steroids & 12 & $24.5 \%$ & 14 & $34.1 \%$ & 26 & $28.9 \%$ \\
\hline Lopinivir/ritonavir & 3 & $6.1 \%$ & 6 & $14.6 \%$ & 9 & $10.0 \%$ \\
\hline Tocilizumab & 7 & $14.3 \%$ & 4 & $9.8 \%$ & 11 & $12.2 \%$ \\
\hline IVIG & 3 & $6.1 \%$ & 4 & $9.8 \%$ & 7 & $7.8 \%$ \\
\hline Plasma & 2 & $4.1 \%$ & 2 & $4.9 \%$ & 4 & $4.4 \%$ \\
\hline Remdesivir & 1 & $2.0 \%$ & 2 & $4.9 \%$ & 3 & $3.3 \%$ \\
\hline \multirow[t]{2}{*}{ Combination of several agents } & 19 & $38.8 \%$ & 15 & $36.6 \%$ & 34 & $37.8 \%$ \\
\hline & 0 & $0.0 \%$ & 0 & $0.0 \%$ & 0 & $0.0 \%$ \\
\hline Vasopressors/inotropes & 20 & $40.8 \%$ & 22 & $53.7 \%$ & 42 & $46.7 \%$ \\
\hline VA ECMO & 5 & $10.2 \%$ & 6 & $14.6 \%$ & 11 & $12.2 \%$ \\
\hline IABP & 2 & $4.1 \%$ & 3 & $7.3 \%$ & 5 & $5.6 \%$ \\
\hline
\end{tabular}

$I V I G$ intravenous immunoglobulin, VA ECMO venoarterial extracorporeal oxygenation, IABP intraaortic balloon pump 
Table 2 Patient characteristics between survivor and nonsurvivors

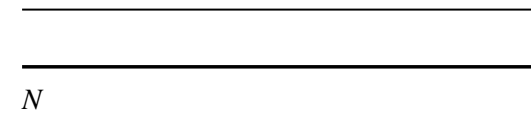

Fever

General

Dyspnea

Cough

Abdominal

Chest pain

Lung infiltrates

Elevated biomarkers

Troponin

Natriuretic peptides

Ferritin

C-reactive protein

Interleukin-6

Electrocardiogram

Prolonged QT

ST elevation

Cardiac risk factors

Diabetes

Hypertension

Other risk factors

Cardiogenic Shock

Echocardiographic findings

Left ventricular ejection fraction, $\%$

Wall motion abnormality

*Apical

*Basal

*Diffuse

*Other

Right ventricular dysfunction

Pericardial effusion

- Moderate

- Large

- Tamponade

Therapy

- Hydroxychloroquine

- Steroids

- Lopinavir/ritpnavir

- Tocilizumab

- IVIG

- Plasma

- Remdesivir

- Combination of agents

- Vasopressors/inotropes

$$
\text { Survivors }
$$

32

24

31

22

10

12

36

41

31

18

33

12

4

14

12

14

12

15

$33.6 \pm 13.1$

11

6

7

4

6

13

5

4

7

19

17

6

9

4

3

2

21

23
Nonsurvivors

N

20

20

$58.2 \%$

$43.6 \%$

$56.4 \%$

$40.0 \%$

$18.2 \%$

$21.8 \%$

$65.5 \%$

$74.5 \%$

$56.4 \%$

$32.7 \%$

$60.0 \%$

$21.8 \%$

$7.3 \%$

$25.5 \%$

$21.8 \%$

$25.5 \%$

$21.8 \%$

$27.3 \%$

15

11

11

12

12

12

0

3

3

12

19

11

$55.0 \%$

$55.0 \%$

$70.0 \%$

$20.0 \%$

$5.0 \%$

$30.0 \%$

$30.0 \%$

$60.0 \%$

$35.0 \%$

$0.0 \%$

$28.6 \pm 12.2$

$20.0 \%$

$40.0 \%$

$10.9 \%$

$15.0 \%$

$12.7 \%$

$15.0 \%$

$7.3 \%$

$0.0 \%$

$10.9 \%$

$30.0 \%$

$23.6 \%$

$20.0 \%$

$\begin{array}{lll}9.1 \% & 1 & 5.0 \%\end{array}$

$\begin{array}{lll}7.3 \% & 3 & 15.0 \%\end{array}$

$\begin{array}{lll}12.7 \% & 4 & 20.0 \%\end{array}$

$\begin{array}{lll}34.5 \% & 7 & 35.0 \%\end{array}$

$30.9 \% \quad 3 \quad 15.0 \%$

$\begin{array}{lll}10.9 \% & 1 & 5.0 \%\end{array}$

$\begin{array}{lll}16.4 \% & 1 & 5.0 \%\end{array}$

$\begin{array}{lll}7.3 \% & 1 & 5.0 \%\end{array}$

$\begin{array}{lll}5.5 \% & 0 & 0.0 \%\end{array}$

$\begin{array}{lll}3.6 \% & 0 & 0.0 \%\end{array}$

$\begin{array}{lll}38.2 \% & 7 & 35.0 \%\end{array}$

$41.8 \% \quad 10 \quad 50 \%$ 


\section{Left ventricular ejection fraction changes}

In majority of patients, LVEF was assessed at least once, and in many repeatedly. The nadir LVEF in the whole study cohort was $31.7 \pm 13.1 \%$ and recovered to $50.1 \pm 16.0 \%$.

The time between the nadir LVEF and recovered LVEF varied widely because the repeat echocardiographic evaluation was not done according to any protocol. In some patients, recovered LVEF was measured or estimated only several months after the discharge at routine follow-ups. Nevertheless, if we limit the cohort to subjects in whom the echocardiogram was repeated during the same admission, the range to LVEF recovery was 2 to 54 days, median 10 days.

There was no difference between the lowest LVEF between men and women (Table 1) or between survivors and nonsurvivors (Table 2). In regard to wall motion characteristics, takotsubo pattern was present in $43.9 \%$, reversed takotsubo in $24.4 \%$, and diffuse or unspecified hypokinesis in $26.8 \%$. Moderate or large pericardial effusion was present in $16 \%$ of patients, with tamponade in $12.5 \%$. Cardiogenic shock developed in 31 patients (32.5\%). Except for older age (65.1 \pm 13.8 vs $49.8 \pm 18.4, p=0.0018)$, nonsurvivors were not different from survivors by the prevalence of cardiac risk factors or symptoms.

\section{Takotsubo syndrome versus myocarditis}

Out of 83 patients who experienced a decrease in LVEF, 30 could be classified as takotsubo syndrome (Table 3 ), and 53 as acute myocarditis (Table 4), based on the reported wall motion pattern. The takotsubo patients were older than

Table 3 COVID-19-positive patients with takotsubo pattern of the wall motion abnormality

\begin{tabular}{|c|c|c|c|c|c|c|c|}
\hline Author, date & Age & Sex & Baseline EF & Recovered EF & $\begin{array}{l}\text { Time to recov- } \\
\text { ery, days }\end{array}$ & $\begin{array}{l}\text { Wall motion: location of } \\
\text { hypokinesis/akinesis }\end{array}$ & Outcome \\
\hline Chao et al. [29] & 49 & M & 40 & 55 & 6 & Basal & Survived \\
\hline Coyle et al. [31] & 57 & M & $35-40$ & 82 & 18 & Basal & Survived \\
\hline Faqihi et al. [32] & 40 & M & 30 & & & Basal & Survived \\
\hline Hedge et al. [33] & 70 & $\mathrm{~F}$ & 45 & & & Basal & Survived \\
\hline Hedge et al. [33] & 58 & M & 40 & Recovered & & Basal & Survived \\
\hline Solano-López et al. [34] & 50 & M & Decreased & Recovered & 10 & Basal & Survived \\
\hline Demetriz et al. [35] & 76 & $\mathrm{~F}$ & 40 & & & Basal & Died \\
\hline Panchal et al. [36] & 65 & M & & & & Basal & Died \\
\hline Bhattacharyya et al. [37] & 32 & $\mathrm{~F}$ & 38 & 51 & 13 & Distal/apical & Survived \\
\hline Bottiroli et al. [38] & 76 & $\mathrm{~F}$ & 25 & 38 & 14 & Distal/apical & Survived \\
\hline Dabbagh et al. [39] & 67 & $\mathrm{~F}$ & 40 & & & Distal/apical & Survived \\
\hline Li et al. [40] & 60 & M & $15-20$ & Normal & 5 & Distal/apical & Survived \\
\hline Oyarzabal et al. [41] & 82 & M & Very depressed & & & Distal/apical & Survived \\
\hline Pasqualetto et al. [30] & 84 & M & 53 & & & Distal/apical & Survived \\
\hline Pasqualetto et al. [30] & 81 & M & 42 & & & Distal/apical & Survived \\
\hline Roca et al. [42] & 87 & $\mathrm{~F}$ & 48 & & & Distal/apical & Survived \\
\hline Sattar et al. [43] & 67 & $\mathrm{~F}$ & 30 & & & Distal/apical & Survived \\
\hline Taza et al. [44] & 52 & M & 45 & & & Distal/apical & Survived \\
\hline Trpkov et al. [45] & 62 & $\mathrm{~F}$ & 24 & 54 & 14 & Distal/apical & Survived \\
\hline Hedge et al. [33] & 71 & $\mathrm{~F}$ & 15 & & & Distal/apical & Died \\
\hline Hedge et al. [33] & 78 & $\mathrm{~F}$ & 20 & & & Distal/apical & Died \\
\hline Hedge et al. [33] & 56 & M & 45 & Recovered & & Distal/apical & Died \\
\hline Karyanna et al. [46] & 72 & $\mathrm{~F}$ & Depressed & & & Distal/apical & Died \\
\hline Park et al. [47] & 78 & $\mathrm{~F}$ & Severely depressed & $\begin{array}{l}\text { Improved with no } \\
\text { ballooning apex }\end{array}$ & 7 & Distal/apical & Died \\
\hline Park et al. [47] & 73 & $\mathrm{~F}$ & & & & Distal/apical & Died \\
\hline Pasqualetto et al. [30] & 85 & $\mathrm{~F}$ & 30 & & & Distal/apical & Died \\
\hline Torabi et al. [48] & 42 & $\mathrm{~F}$ & 20 & & & Distal/apical & Died \\
\hline Minhas et al. [49] & 58 & $\mathrm{~F}$ & 20 & 55 & 6 & Distal/apical & Unknown \\
\hline Khalid et al. [50] & 76 & $\mathrm{~F}$ & 55 & 59 & & Distal/apical & Unknown \\
\hline Bernardi et al. [51] & 74 & M & 22 & 57 & 14 & Distal/apical & Unknown \\
\hline
\end{tabular}


Table 4 COVID-19-positive patients with diffuse or unspecified pattern of the wall motion abnormality

\begin{tabular}{|c|c|c|c|c|c|c|}
\hline Author, date & Age & Sex & Baseline LVEF & Recovered LVEF & $\begin{array}{l}\text { Days to } \\
\text { recovery }\end{array}$ & Outcome \\
\hline Anupama et al. [52] & 66 & M & 32 & $60-65$ & 10 & Survived \\
\hline Ashok and Loke [53] & 53 & M & Mildly depressed & & & Survived \\
\hline $\begin{array}{l}\text { Bernal-Torres et al. } \\
\text { [54] }\end{array}$ & 38 & $\mathrm{~F}$ & 30 & Normal & 14 & Survived \\
\hline Blaivas [55] & 46 & M & $40-45$ & 50 & 7 & Survived \\
\hline Blaivas [55] & 21 & M & $25-30$ & & & Survived \\
\hline Bonnet et al. [56] & 27 & M & 20 & 40 & 30 & Survived \\
\hline Chitturi et al. [57] & 65 & $\mathrm{~F}$ & 25 & 64 & 2 & Survived \\
\hline Cuomo et al. [58] & 49 & $\mathrm{~F}$ & 45 & 55 & 7 & Survived \\
\hline Dalen et al. [59] & 55 & $\mathrm{~F}$ & 46 & 60 & 10 & Survived \\
\hline De Vito et al. [60] & 35 & $\mathrm{~F}$ & 20 & 20 & 4 & Survived \\
\hline Garau & 18 & $\mathrm{~F}$ & 10 & 20 & 45 & Survived \\
\hline Garot et al. [61] & 18 & M & 30 & 54 & 14 & Survived \\
\hline Gay et al. [62] & 56 & M & 5 & 50 & 4 & Survived \\
\hline Gomez et al. [63] & 54 & $\mathrm{~F}$ & $25-30$ & $70-75$ & 13 & Survived \\
\hline $\begin{array}{l}\text { Gomila-Grange et al. } \\
\text { [64] }\end{array}$ & 39 & M & 30 & Normal & 10 & Survived \\
\hline Khalid et al. [65] & 48 & M & 45 & & & Survived \\
\hline Khalid et al. [65] & 34 & $\mathrm{~F}$ & 25 & Normal & 3 & Survived \\
\hline Luetkens et al. [66] & 79 & M & 49 & & & Survived \\
\hline Naneishvili et al. [67] & 44 & $\mathrm{~F}$ & 37 & Normal & 2 & Survived \\
\hline Oleszak et al. [68] & 52 & M & $15-20$ & $20-25$ & 5 & Survived \\
\hline Parsova et al. [69] & 58 & $\mathrm{~F}$ & 30 & 50 & 180 & Survived \\
\hline Paul et al. [70] & 35 & M & & & & Survived \\
\hline Pavon et al. [71] & 64 & M & 42 & 47 & 3 & Survived \\
\hline Yeleti et al. [21] & 25 & $\mathrm{~F}$ & 10 & 50 & 2 & Survived \\
\hline Richard et al. [72] & 28 & $\mathrm{~F}$ & $25-30$ & 55 & 3 & Survived \\
\hline Rubartelli et al. [73] & 43 & M & 20 & 23 & 56 & Survived \\
\hline Sala et al. [8] & 43 & $\mathrm{~F}$ & 43 & & & Survived \\
\hline Salamanca et al. [74] & 44 & M & 15 & 75 & 14 & Survived \\
\hline Sampaio et al. [75] & 45 & $\mathrm{~F}$ & Decreased & Improved & & Survived \\
\hline Tsao et al. [76] & 59 & $\mathrm{~F}$ & 36 & Normal & 10 & Survived \\
\hline Vilaro et al. [77] & 50 & M & 40 & Normal & 8 & Survived \\
\hline Yuan et al. [78] & 33 & M & Slightly decreased & & & Survived \\
\hline Gomez et al. [63] & 53 & M & 35 & & & Died \\
\hline Hakmi et al. [79] & 56 & M & 20 & & & Died \\
\hline Hakmi et al. [79] & 55 & M & Decreased & & & Died \\
\hline Hedge et al. [33] & 88 & M & 30 & Recovered & & Died \\
\hline Kazi et al. [80] & 73 & M & 25 & 70 & 14 & Died \\
\hline $\begin{array}{l}\text { Khatri and Wallach } \\
\text { [81] }\end{array}$ & 50 & M & Severely decreased & & & Died \\
\hline Radbel et al. [82] & 40 & M & Mildly decreased & & & Died \\
\hline Sang et al. [13] & 58 & $\mathrm{~F}$ & Severely decreased & & & Died \\
\hline Tavazzi et al. [7] & 69 & M & 25 & Normal & 4 & Died \\
\hline Zeng et al. [83] & 63 & M & 32 & 68 & 14 & Died \\
\hline Hussain et al. [84] & 51 & M & 20 & & & Unknown \\
\hline Inciardi et al. [85] & 53 & $\mathrm{~F}$ & 35 & 44 & 6 & Unknown \\
\hline Fried et al. [86] & 38 & M & $20-25$ & & & Unknown \\
\hline Fried et al. [86] & 64 & $\mathrm{~F}$ & 30 & 50 & 10 & Unknown \\
\hline Kim et al. [87] & 21 & $\mathrm{~F}$ & Severely decreased & & & Unknown \\
\hline Hu et al. [88] & 37 & M & 27 & & & Unknown \\
\hline
\end{tabular}


Table 4 (continued)

\begin{tabular}{|c|c|c|c|c|c|c|}
\hline Author, date & Age & Sex & Baseline LVEF & Recovered LVEF & $\begin{array}{l}\text { Days to } \\
\text { recovery }\end{array}$ & Outcome \\
\hline Spano et al. [89] & 49 & M & Severely decreased & & & Unknown \\
\hline Juusela et al. [90] & 45 & $\mathrm{~F}$ & 40 & & & Unknown \\
\hline Juusela et al. [90] & 26 & $\mathrm{~F}$ & $40-45$ & & & Unknown \\
\hline $\begin{array}{l}\text { Irabien-Ortiz et al. } \\
\text { [91] }\end{array}$ & 59 & $\mathrm{~F}$ & Severely decreased & Normal & 4 & Unknown \\
\hline Rassaf et al. [92] & 30 & M & 23 & & & Unknown \\
\hline
\end{tabular}

those with myocarditis, with mean age $65.0 \pm 14.8$ years versus $47.2 \pm 15.5$, respectively $(p<0.001)$. In the myocarditis cohort, $31(58.5 \%)$ were males. In the takotsubo cohort, 13 $(43.3 \%)$ were males.

The LVEF was not different between takotsubo and myocarditis ( $32.8 \pm 11.2 \%$ vs $29.3 \pm 9.1 \%$, respectively), nor was the time to LVEF recovery $(10.7 \pm 10.0$ days vs $9.8 \pm 9.1$ days, respectively) (Table 5).

\section{Cardiogenic shock}

We considered that the patients had cardiogenic shock if they required vasopressors, inotropes, and/or mechanical circulatory support (MCS), and no positive blood cultures/septic shock was reported. By these criteria, cardiogenic shock occurred in $33(33.6 \%)$ patients in the whole cohort. The mean age was $53.5 \pm 17.5$ years of age, which was similar to the whole cohort, and there was almost equal representation of males $(48.5 \%)$ and females. In majority of them (19/57.6\%), cardiogenic shock was either present on admission, or developed in the first hours after the admission, but in some, this condition developed later in the course of the disease, up to 2 weeks. Fifteen survived, 9 died, and in the rest, the outcome was either unknown at the time of publication or not reported. Thus, from the patients with known outcomes, $57.6 \%$ survived to discharge. VA ECMO was used in 9 cases, including five patients who also were supported with intraaortic balloon pump or Impella, and in three more cases, either balloon pump or Impella were used without ECMO, bringing the use of mechanical circulatory support devices to $36.4 \%$. Six patients, supported by MCS, survived, 3 died, in the rest the outcomes are unknown. Twelve of the 33 patients had wall motion abnormality in the pattern of either apical or basal hypokinesis/akinesis (takotsubo and reverse takotsubo), and in the rest, hypokinesis was diffuse. There were survivors and nonsurvivors in any pattern of wall motion abnormality: 4 and 4 in the takotsubo subset and 11 and 5 in the diffuse hypokinesis subset.

\section{Cardiac magnetic resonance}

Cardiac magnetic resonance (CMR) results were available for 25 patients. This diagnostic study was performed almost exclusively in patients with diffuse hypokinesis of the left ventricle (as opposed to takotsubo or reverse takotsubo pattern). Interestingly, six of these patients had completely normal LVEF $(\geq 50 \%)$. There are three MRI sequences that are critical in the diagnosis of myocarditis. They can identify edema (T2-weighted images), hyperemia (T1-weighted images, early gadolinium enhancement), and necrosis (late gadolinium enhancement (LGE)). While the first two methods mostly reflect reversible injury related to inflammation, LGE identifies irreversible damage such as necrosis and fibrosis [6].

In 7 patients, all three CMR criteria for myocarditis were met. Two out of three features were found in 9 patients, either edema T2 and late gadolinium enhancement (6) or only edema and hyperemia (3), and in 8 only one criterion was present, either myocardial edema (5) of late gadolinium enhancement (3). In one patient, no signs of myocarditis could be found.

\section{Endomyocardial biopsy}

Among survivors, 6 biopsied were performed, two demonstrated lymphocytic myocarditis with no COVID-19 genome and one with parvovirus and three were negative for any diagnostic findings including myocarditis. In two patients with negative biopsy, CMR was also performed and was consistent with myocardial edema in one case and the presence of necrosis by late gadolinium enhancement in 45 days after the presentation. In one of the two cases with lymphocytic myocarditis, the CMR was positive for myocardial edema and hyperemia, with no late gadolinium enhancement. In one more case, Tavazzi et al. [7] identified COVID-19 particles in the bioptate; however, no viral genome analysis was reported.

Interestingly, one of the cases with acute myocarditis confirmed on both endomyocardial biopsy and CMR was initially considered to represent reverse takotsubo based on the wall motion pattern [8]. 
Table 5 Takotsubo/reversed takotsubo versus diffuse wall motion abnormality

\begin{tabular}{|c|c|c|c|c|}
\hline & Takotsubo & & Myocarditis & \\
\hline Total & 30 & $100.0 \%$ & 53 & $100.0 \%$ \\
\hline \multicolumn{5}{|l|}{ Symptoms } \\
\hline - Fever & 18 & $60.0 \%$ & 23 & $43.4 \%$ \\
\hline - General & 12 & $40.0 \%$ & 27 & $50.9 \%$ \\
\hline - Dyspnea & 20 & $66.7 \%$ & 32 & $60.4 \%$ \\
\hline - Cough & 16 & $53.3 \%$ & 14 & $26.4 \%$ \\
\hline - Abdominal pain & 3 & $10.0 \%$ & 5 & $9.4 \%$ \\
\hline - Chest pain & 6 & $20.0 \%$ & 11 & $20.8 \%$ \\
\hline Upper respiratory & 0 & $0.0 \%$ & 2 & $3.8 \%$ \\
\hline Lung infiltrates & 19 & $63.3 \%$ & 37 & $69.8 \%$ \\
\hline QT & 4 & $13.3 \%$ & 1 & $1.9 \%$ \\
\hline ST elevation & 11 & $36.7 \%$ & 11 & $20.8 \%$ \\
\hline \multicolumn{5}{|l|}{ Cardiac risk factors } \\
\hline - Diabetes & 11 & $36.7 \%$ & 11 & $20.8 \%$ \\
\hline - Hypertension & 18 & $60.0 \%$ & 18 & $34.0 \%$ \\
\hline \multicolumn{5}{|l|}{ Pericardial effusion } \\
\hline - Moderate & 2 & $6.7 \%$ & 7 & $13.2 \%$ \\
\hline - Large & 1 & $3.3 \%$ & 5 & $9.4 \%$ \\
\hline - Tamponade & 2 & $6.7 \%$ & 8 & $15.1 \%$ \\
\hline \multicolumn{5}{|l|}{ Treatment } \\
\hline Hydroxychloroquine & 14 & $46.7 \%$ & 20 & $37.7 \%$ \\
\hline Steroids & 8 & $26.7 \%$ & 18 & $34.0 \%$ \\
\hline Lopinavir/ritpnavir & 3 & $10.0 \%$ & 6 & $11.3 \%$ \\
\hline Tocilizumab & 4 & $13.3 \%$ & 8 & $15.1 \%$ \\
\hline IVIG & 1 & $3.3 \%$ & 4 & $7.5 \%$ \\
\hline Plasma & 0 & $0.0 \%$ & 3 & $5.7 \%$ \\
\hline Remdesivir & 0 & $0.0 \%$ & 3 & $5.7 \%$ \\
\hline Combination of agents & 14 & $46.7 \%$ & 21 & $39.6 \%$ \\
\hline Vasopressors/inotropes & 14 & $46.7 \%$ & 26 & $49.1 \%$ \\
\hline VA ECMO & 1 & $3.3 \%$ & 6 & $11.3 \%$ \\
\hline IABP & 1 & $3.3 \%$ & 3 & $5.7 \%$ \\
\hline Impella & 0 & $0.0 \%$ & 1 & $1.9 \%$ \\
\hline \multicolumn{5}{|l|}{ Outcomes } \\
\hline Survived & 17 & $56.7 \%$ & 32 & $60.4 \%$ \\
\hline Died & 10 & $33.3 \%$ & 10 & $18.9 \%$ \\
\hline Unknown & 3 & $10.0 \%$ & 10 & $18.9 \%$ \\
\hline
\end{tabular}

IVIG intravenous immunoglobulin, VA ECMO venoarterial extracorporeal oxygenation, $I A B P$ intraaortic balloon pump

\section{Discussion}

In this systematic literature review, we summarized the collective worldwide experience with myocardial involvement in COVID-19-infected patients. The overwhelming effect of the pandemic mandated expedited publication process as the professional community struggled to understand this new entity. As a result, many case reports and case series were published, but a significant proportion of them lacks important details. Moreover, many cases were submitted and published while the patient remained hospitalized, and the outcomes was unknown. Nevertheless, the sum experience is valuable.

Subclinical changes in cardiac structure and function occur in many patients with COVID-19. Such changes manifest as reduced longitudinal strain observed predominantly in basal LV segments, resembling a reversed takotsubo pattern (71\%), or alterations in radial and circumferential strain [9]. Acute and remote significance of such changes are unknown, we also do not know yet whether they resolve completely with the recovery from the acute viral process.

On CMR, patients who survived COVID-19 with pulmonary symptoms, no signs of HF, and elevated troponin levels, had pericardial effusions in $7 \%$ of cases, and myocarditislike pattern on late gadolinium enhancement in $45 \%$ of cases [10]. In another study, 54\% of patients with COVID-19 and nonspecific symptoms of chest discomfort or palpitations had myocardial edema, and $31 \%$ of cases had evidence of small focal subepicardial and patchy mid-wall LGE in a pattern consistent with myocarditis. All of them had normal troponin levels at the time of CMR, and only half of them had elevated troponin during the acute infection [11].

However, in clinical practice, it is important to know what happens to the patients who have clinical evidence of myocardial involvement.

Majority of cases with clinically relevant myocardial involvement $(>60 \%$ ) had acute bilateral pulmonary process typical for COVID-19. Other investigators reported that ECG changes, such as ST depression, T-wave inversion, ST-T changes, and the presence of fractionated QRS in COVID-19 are closely associated with severity of the viral infection [12].

In terms of clinical entities, most authors, reporting the cases or case series, categorized their patients into two categories based on the pattern of wall motion abnormality: myocarditis or stress-induced cardiomyopathy. A distinct pattern of the wall motion abnormality, specifically predominantly distal and apical akinesis/hypokinesis, or basal hypokinesis/akinesis, usually placed patients into the takotsubo or reversed takotsubo syndrome, respectively. Diffuse hypokinesis or decreased LVEF with no specific pattern reported, typically was reported as myocarditis. This division has to be interpreted with caution, because such distinctions are not absolute, and in at least one patient, who was thought to have a takotsubo cardiomyopathy based on the wall motion pattern, the CMR confirmed acute myocarditis [8]. Nevertheless, we compared patients based on the wall motion pattern. Doing this, we did not always go with the authors' diagnosis. For instance, Sang et al. [13] reported a case of takotsubo cardiomyopathy, but they described a diffuse pattern of severe LV hypokinesis with some apical predominance and signs 
of myocarditis on the autopsy. We analyzed this case as presumed myocarditis with diffuse LV hypokinesis.

Takotsubo cardiomyopathy in COVID-19 is not infrequent. Other studies summarizing reported cases had a female predominance of $66 \%$ and mean age of $70.8 \pm 15.2$ years [14] — not too different from our cohort, likely because the same cases from the literature were included. Other reports had an almost even representation of males and females in takotsubo syndrome in COVID-19 [15], which is unusual because typical takotsubo cohorts have an overwhelming female predominance. Thus, in a large Japanese registry, female patients accounted for $77.2 \%$ [16], while in the Western countries, the share of women reaches $91 \%$ [17]. Interestingly, the stressful event that triggered this stressinduced cardiomyopathy was identified in only 3 of 12 cases [14]. One can speculate that the very fact of being diagnosed with COVID-19 could be that stressful event. On the other hand, there is at least one known case where a characteristic echocardiographic pattern suggested the diagnosis of takotsubo, while the CMR and biopsy confirmed acute myocarditis. Because CMR and endomyocardial biopsy are rarely done-in fact, neither was performed in a single other case where clinical diagnosis, based on presentation and imaging, suggested takotsubo syndrome-we were reluctant to upfront categorize the published cases into takotsubo versus myocarditis and analyzed the whole cohort with myocardial involvement instead. Some other cases classified as takotsubo could, in fact, represent myocarditis. Other researchers also cautioned that in the absence of CMR, myocarditis can be misinterpreted as takotsubo [15].

Acute lymphocytic myocarditis is not uncommon in COVID-19. On the autopsy of 21 consecutive COVID-19 patients, myocarditis, defined as the presence of multiple foci of inflammation with associated myocyte injury, was present in $14 \%$ of the cases. Pericarditis and acute right ventricular injury were also identified [18].

The mechanism of myocardial inflammation in COVID19 is not well established. The virus can trigger immune response in the form of cytokine storm releasing IL-6, IL-10, and TNF-alpha causing myocarditis. In two cases, there was an evidence of the viral presence in the myocardium [7, 19]. The unique affinity of COVID-19 to angiotensin-converting enzyme 2 receptor creates the potential for direct viral infection of the myocardium [20].

Another potential mechanism is that COVID-19 makes patients more susceptible to myocarditis caused by other pathogens. We reported a case of fulminant myocarditis, confirmed by CMR, in a young COVID-19-positive patient. Should we have not sent the sample for a viral genome, we would have little doubt that the myocarditis was due to COVID-19; however, the genome test returned positive for parvovirus [21]. This observation is not unique. Shah et al. noticed a high $(22 \%)$ co-infection rate in patients with coronavirus [22, 23]. Of course, some patients could have falsepositive tests for COVID-19 as well.

It is known that patients, who die as a result of COVID-19, have more comorbidities, more severe inflammation and active coagulation factors, and higher levels of myocardial biomarkers [24]. However, in the present study, we could not confirm that in patients with decreased LVEF.

It is interesting that the degree of LV dysfunction and the pace of recovery did not differ between patients with a takotsubo/reversed takotsubo pattern of wall motion abnormality and diffuse LV hypokinesis.

Another characteristic feature of COVID-19-related cardiac injury is a high prevalence of pericardial effusion (23.3\%), and most importantly the cardiac tamponade $(12.2 \%)$.

It was reported before that the presence of pericardial effusion often signifies systemic and myocardial inflammation and may predict poor prognosis [25]. The presence of COVID-19 in pericardial fluid has been recently reported [26]. Also, viral particles in pericardial effusion were seen on electron microscopy [27]. From our standpoint, this is a sufficient reason to include early echocardiography into the standard work-up of symptomatic COVID-19 patients.

The autopsy of 9 patients with COVID-19 who either died suddenly or had cardiogenic shock demonstrated lymphomononuclear infiltrates in the myocardium with focal necrosis of adjacent myocytes and pericardial effusion. There were also inflammatory changes in the subepicardial ganglia and HisPurkinje system. No viral genomes were identified.[28].

Finally, it is important to note that pharmaceutical management of the patients does not reflect currently approved regimen. The most common regimen included hydroxychloroquine as well as steroids, but remdesevir and convalescent plasma have only been used in few. There was no noticeable use of monoclonal antibodies, that ultimately gained emergency approval in November 2020. The multinational origin of the reports and scatter of the cases throughout the whole calendar year of 2020 with rapidly changing recommendations likely account for this.

In summary, COVID-related myocardial involvement occurs in patients with severe respiratory damage, manifests as a rapid and mostly reversible left ventricular systolic dysfunction, and may have a pattern of selective distal, selective proximal, or diffuse hypokinesis. Preservation of normal left ventricular ejection fraction or presence of wall motion abnormalities rather than diffuse hypokinesis does not rule out myocarditis. Pericardial effusion is common, and tamponade occurs in $12 \%$ of the patients, justifying early echocardiographic evaluation. Cardiogenic shock complicates one third of the cases and often requires mechanical circulatory support. 


\section{References}

1. Bonow RO, Fonarow GC, O'Gara PT, Yancy CW (2020) Association of coronavirus disease 2019 (COVID-19) with myocardial injury and mortality. JAMA Cardiology 5:751-753

2. Shi S, Qin M, Cai Y, Liu T, Shen B, Yang F et al (2020) Characteristics and clinical significance of myocardial injury in patients with severe coronavirus disease 2019. Eur Heart J 41:2070-2079

3. Cruz Rodriguez JB, Lange RA, Mukherjee D (2020) Gamut of cardiac manifestations and complications of COVID-19: a contemporary review. J Investig Med 68(8):1334-1340

4. Rey JR, Caro-Codón J, Rosillo SO, Iniesta ÁM, Castrejón-Castrejón S, Marco-Clement I et al (2020) Heart failure in COVID-19 patients: prevalence, incidence and prognostic implications. Eur J Heart Fail 22(12):2205-2215

5. Moher D, Liberati A, Tetzlaff J, Altman DG, Group P (2009) Preferred reporting items for systematic reviews and meta-analyses: the PRISMA statement. PLoS Med 6:e1000097

6. Ferreira VM, Schulz-Menger J, Holmvang G, Kramer CM, Carbone I, Sechtem U et al (2018) Cardiovascular Magnetic Resonance in Nonischemic Myocardial Inflammation: expert Recommendations. J Am Coll Cardiol 72:3158-3176

7. Tavazzi G, Pellegrini C, Maurelli M, Belliato M, Sciutti F, Bottazzi A et al (2020) Myocardial localization of coronavirus in COVID19 cardiogenic shock. Eur J Heart Fail 22:911-915

8. Sala S, Peretto G, Gramegna M, Palmisano A, Villatore A, Vignale $D$ et al (2020) Acute myocarditis presenting as a reverse TakoTsubo syndrome in a patient with SARS-CoV-2 respiratory infection. Eur Heart J 41:1861-1862

9. Stöbe S, Richter S, Seige M, Stehr S, Laufs U, Hagendorff A (2020) Echocardiographic characteristics of patients with SARSCoV-2 infection. Clinicalresearch in cardiology: official journal of the German Cardiac Society 109(12):1549-1566

10. Knight DS, Kotecha T, Razvi Y, Chacko L, Brown JT, Jeetley PS et al (2020) COVID-19: Myocardial Injury in Survivors. Circulation 142:1120-1122

11. Huang L, Zhao P, Tang D, Zhu T, Han R, Zhan C et al (2020) Cardiac involvement in patients recovered from COVID-2019 identified using magnetic resonance imaging. JACC Cardiovasc Imaging 13:2330-2339

12. Barman HA, Atici MDA, Alici MDG, Sit MDO, Tugrul MDS, Gungor MDB, et al (2020) The effect of the severity COVID-19 infection on electrocardiography. Am J Emerg Med S0735-6757(20)30889-5

13. Sang CJ 3rd, Heindl B, Von Mering G, Brott B, Kopf RS, Benson PV et al (2020) Stress-Induced Cardiomyopathy Precipitated by COVID19 and Influenza A Coinfection. JACC Case reports 2:1356-1358

14. Singh S, Desai R, Gandhi Z, Fong HK, Doreswamy S, Desai V, et al (2020) Takotsubo syndrome in patients with COVID-19: a systematic review of published cases. SN Comprehensive Clinical Medicine 1-7

15. Finsterer J (2020) Letter by Finsterer regarding article, "COVID19-associated stress (takotsubo) cardiomyopathy." Circ Cardiovasc Imaging 13:e011577

16. Murakami T, Yoshikawa T, Maekawa Y, Ueda T, Isogai T, Sakata $\mathrm{K}$ et al (2015) Gender differences in patients with takotsubo cardiomyopathy: multi-center registry from Tokyo CCU Network. PloS One 10:e136655

17. Schneider B, Athanasiadis A, Stöllberger C, Pistner W, Schwab J, Gottwald U et al (2013) Gender differences in the manifestation of tako-tsubo cardiomyopathy. Int J Cardiol 166:584-588

18. Basso C, Leone O, Rizzo S, De Gaspari M, van der Wal AC, Aubry MC et al (2020) Pathological features of COVID-19-associated myocardial injury: a multicentre cardiovascular pathology study. Eur Heart J41(39):3827-3835
19. Dolhnikoff M, Ferreira Ferranti J, de Almeida Monteiro RA, Duarte-Neto AN, Soares Gomes-Gouvêa M, Viu Degaspare $\mathrm{N}$ et al (2020) SARS-CoV-2 in cardiac tissue of a child with COVID-19-related multisystem inflammatory syndrome. Lancet Child Adolesc Health 4:790-794

20. Turner AJ, Hiscox JA, Hooper NM (2004) ACE2: from vasopeptidase to SARS virus receptor. Trends Pharmacol Sci 25:291-294

21. Yeleti R, Guglin M, Saleem K, Adigopula SV, Sinha A, Upadhyay S, et al (2021) Fulminant myocarditis: COVID or not COVID? Reinfection or co-infection? Future Cardiol. https://doi.org/10. 2217/fca-2020-0237

22. Shah J, Kumar S, Patel A (2020) Myocarditis and pericarditis in patients with COVID-19. Heart Views 21:209-14

23. Kim D, Quinn J, Pinsky B, Shah NH, Brown I (2020) Rates of Coinfection between SARS-CoV-2 and other respiratory pathogens. JAMA 323:2085-2086

24. Yang C, Liu F, Liu W, Cao G, Liu J, Huang S et al (2020) Myocardial injury and risk factors for mortality in patients with COVID19 pneumonia. Int J Cardiol 326:230-236

25. Duerr GD, Heine A, Hamiko M, Zimmer S, Luetkens JA, Nattermann J et al (2020) Parameters predicting COVID-19-induced myocardial injury and mortality. Life Sci 260:118400

26. Dabbagh MF, Aurora L, D'Souza P, Weinmann AJ, Bhargava P, Basir MB (2020) Cardiac tamponade secondary to COVID-19. JACC Case reports 2:1326-1330

27. García-Cruz E, Manzur-Sandoval D, Lazcano-Díaz EA, SoriaCastro E, Jiménez-Becerra S (2020) Cardiac tamponade in a patient with myocardial infarction and COVID-19: electron microscopy. JACC Case reports 2:2021-2023

28. Del Nonno F, Frustaci A, Verardo R, Chimenti C, Nicastri E, Antinori A, et al (2020) Virus-Negative Myopericarditis in Human Coronavirus Infection: Report From an Autopsy Series. Circ Heart Failure 12:e007636

29. Chao CJ, DeValeria PA, Sen A, Sc M, Lee H, Pedrotty DM, et al (2020) Reversible cardiac dysfunction in severe COVID-19 infection, mechanisms and case report. Echocardiography (Mount Kisco, NY). 37(9):1465-1469

30. Pasqualetto MC, Secco E, Nizzetto M, Scevola M, Altafini L, Cester A et al (2020) Stress cardiomyopathy in COVID-19 disease. Eur J Case Rep Intern Med 7:001718

31. Coyle J, Igbinomwanhia E, Sanchez-Nadales A, Danciu S, Chu C, Shah N (2020) A recovered case of COVID-19 myocarditis and ARDS treated with corticosteroids, tocilizumab, and experimental AT-001. JACC Case reports 2:1331-1336

32. Faqihi F, Alharthy A, Alshaya R, Papanikolaou J, Kutsogiannis DJ, Brindley PG et al (2020) Reverse takotsubo cardiomyopathy in fulminant COVID-19 associated with cytokine release syndrome and resolution following therapeutic plasma exchange: a casereport. BMC Cardiovasc Disord 20:389

33. Hegde S, Khan R, Zordok M, Maysky M (2020) Characteristics and outcome of patients with COVID-19 complicated by Takotsubo cardiomyopathy: case series with literature review. Open Heart 7(2): 001360

34. Solano-López J, Sánchez-Recalde A, Zamorano JL (2020) SARSCoV-2, a novel virus with an unusual cardiac feature: inverted takotsubo syndrome. Eur Heart J 41:3106

35. Demertzis ZD, Dagher C, Malette KM, Fadel RA, Bradley PB, Brar I et al (2020) Cardiac sequelae of novel coronavirus disease 2019 (COVID-19): a clinical case series. Eur Heart J Case Rep 4:1-6

36. Panchal A, Kyvernitakis A, Biederman R (2020) An interesting case of COVID-19 induced reversed takotsubo cardiomyopathy and insight on cardiac biomarkers. Cureus 12:e11296

37. Bhattacharyya PJ, Attri PK, Farooqui W (2020) Takotsubo cardiomyopathy in early term pregnancy: a rare cardiac complication of SARS-CoV-2 infection. BMJ Case Reports 13(9):e239104 
38. Bottiroli M, De Caria D, Belli O, Calini A, Andreoni P, Siragusa A et al (2020) Takotsubo syndrome as a complication in a critically ill COVID-19 patient. ESC Heart Fail 7(6):4297-4300

39. Dabbagh MF, Aurora L, D'Souza P, Weinmann AJ, Bhargava P, Basir MB (2020) Cardiac tamponade secondary to COVID-19. JACC: Case Reports 2:1326-30

40. Li A, Garcia-Bengochea Y, Stechel R, Azari BM (2020) Management of COVID-19 myopericarditis with reversal of cardiac dysfunction after blunting of cytokine storm: a case report. Eur Heart J Case Rep 4:1-6

41. Oyarzabal L, Gómez-Hospital JA, Comin-Colet J (2020) Tako-tsubo syndrome associated with COVID-19. Revista espanola de cardiologia (English ed) 73:846

42. Roca E, Lombardi C, Campana M, Vivaldi O, Bigni B, Bertozzi B et al (2020) Takotsubo syndrome associated with COVID-19. Eur J Case Rep Intern Med 7:001665

43. Sattar Y, Connerney M, Ullah W, Philippou A, Slack D, McCarthy B et al (2020) COVID-19 presenting as takotsubo cardiomyopathy complicated with atrial fibrillation. Int J Cardiol Heart Vasc 29:100580

44. Taza F, Zulty M, Kanwal A, Grove D (2020) Takotsubo cardiomyopathy triggered by SARS-CoV-2 infection in a critically ill patient. BMJ Case Reports 13(6):e236561

45. Trpkov C, MacMullan P, Feuchter P, Kachra R, Heydari B, Merchant $\mathrm{N}$ et al (2020) Rapid response to cytokine storm inhibition using anakinra in a patient with COVID-19 myocarditis. CJC Open 3(2):210-213

46. Kariyanna PT, Chandrakumar HP, Jayarangaiah A, Khan A, Vulkanov V, Ashamalla M et al (2020) Apical takotsubo cardiomyopathy in a COVID-19 patient presenting with stroke: a case report and pathophysiologic insights. Am J Med Case Rep 8:350-357

47. Park JH, Moon JY, Sohn KM, Kim YS (2020) Two fatal cases of stress-induced cardiomyopathy in COVID-19 patients. J Cardiovasc Imaging 28:300-303

48. Torabi AJ, Villegas-Galaviz J, Guglin M, Frick K, Rao R (2020) Cardiogenic shock following cardiac tamponade and Takotsubo in COVID-19. Futur Cardiol 17(4):631-635

49. Minhas AS, Scheel P, Garibaldi B, Liu G, Horton M, Jennings M et al (2020) Takotsubo Syndrome in the Setting of COVID-19. JACC Case reports 2:1321-1325

50. Khalid Y, Dasu N, Dasu K (2020) A case of novel coronavirus (COVID-19)-induced viral myocarditis mimicking a Takotsubo cardiomyopathy. HeartRhythm case reports 6:473-476

51. Bernardi N, Calvi E, Cimino G, Pascariello G, Nardi M, Cani D et al (2020) COVID-19 pneumonia, takotsubo syndrome, and left ventricle thrombi. JACC Case reports 2:1359-1364

52. Anupama BK, Thapa SS, Amzuta I (2020) Transient cardiomyopathy in a patient with coronavirus disease-2019. J Investig Med High Impact Case Rep 8:2324709620947577

53. Ashok V, Loke WI (2020) Case report: high-grade atrioventricular block in suspected COVID-19 myocarditis. Eur Heart J Case Rep 4:1-6

54. Bernal-Torres W, Herrera-Escandón Á, Hurtado-Rivera M, PlataMosquera CA (2020) COVID-19 fulminant myocarditis: a case report. Eur Heart J Case Rep 4:1-6

55. Blaivas M (2020) Unexpected finding of myocardial depression in 2 healthy young patients with COVID-19 pneumonia: possible support for COVID-19-related myocarditis. J Am Coll Emerg Physicians Open 1:375-378

56. Bonnet M, Craighero F, Harbaoui B (2020) Acute myocarditis with ventricular noncompaction in a COVID-19 patient. JACC Heart failure 8:599-600

57. Chitturi KR, Thacker S, Al-Saadi MA, Kassi M (2020) Successful treatment of acute heart failure in COVID-19-induced cytokine storm with tocilizumab: a case report. Eur Heart J Case Rep 4:1-6
58. Cuomo V, Esposito R, Santoro C (2020) Fulminant myocarditis in the time of coronavirus. Eur Heart J 41:2121

59. Dalen H, Holte E, Guldal AU, Hegvik JA, Stensaeth KH, Braaten AT et al (2020) Acute perimyocarditis with cardiac tamponade in COVID-19 infection without respiratory disease. BMJ Case Reports 13(8):e236218

60. De Vita S, Ippolito S, Caracciolo MM, Barosi A (2020) Peripartum cardiomyopathy in a COVID-19-infected woman: differential diagnosis with acute myocarditis-A case report from a Hub Institution during the COVID-19 outbreak. Echocardiography (Mount Kisco, NY) 37(10):1673-1677

61. Garot J, Amour J, Pezel T, Dermoch F, Messadaa K, Felten ML et al (2020) SARS-CoV-2 Fulminant Myocarditis. JACC Case reports 2:1342-1346

62. Gay HC, Sinha A, Michel E, Mozer AB, Budd A, Feinstein MJ et al (2020) Fulminant myocarditis in a patient with coronavirus disease 2019 and rapid myocardial recovery following treatment. ESC Heart Fail 7(6):4367-4370

63. Gómez HL, Bielsa AP, Banzo MJA (2020) Fulminant myocarditis and cardiogenic shock during SARS-CoV-2 infection. Medicina Clinica (English ed) 155(10):463-464

64. Gomila-Grange A, Espasa M, Moglia E (2020) Cardiogenic shock caused by SARS-CoV-2 in a patient with serial negative nucleic acid amplification tests. Case Report. SN comprehensive clinical medicine 1-3

65. Khalid N, Chen Y, Case BC, Shlofmitz E, Wermers JP, Rogers T et al (2020) COVID-19 (SARS-CoV-2) and the heart - an ominous association. Cardiovasc Revasc Med 21:946-949

66. Luetkens JA, Isaak A, Zimmer S, Nattermann J, Sprinkart AM, Boesecke C et al (2020) Diffuse myocardial inflammation in COVID-19 associated myocarditis detected by multiparametric cardiac magnetic resonance imaging. Circ Cardiovasc Imaging 13:e010897

67. Naneishvili T, Khalil A, O'Leary R, Prasad N (2020) Fulminant myocarditis as an early presentation of SARS-CoV-2. BMJ Case Reports 13(9):e237553

68. Oleszak F, Maryniak A, Botti E, Abrahim C, Salifu MO, Youssef $M$ et al (2020) Myocarditis associated With COVID-19. Am J Med Case Rep 8:498-502

69. Parsova KE, Pay L, Oflu Y, Hacıyev R, Çinier G (2020) A rare presentation of a patient with COVID-19: Cardiac tamponade. Turk Kardiyoloji Dernegi arsivi : Turk Kardiyoloji Derneginin yayin organidir 48:703-706

70. Paul JF, Charles P, Richaud C, Caussin C, Diakov C (2020) Myocarditis revealing COVID-19 infection in a young patient. Eur Heart J Cardiovasc Imaging 21:776

71. Pavon AG, Meier D, Samim D, Rotzinger DC, Fournier S, Marquis $P$ et al (2020) First documentation of persistent SARS-Cov-2 infection presenting with late acute severe myocarditis. Can J Cardiol 36:1326. e5-.e7

72. Richard I, Robinson B, Dawson A, Aya A, Ali R (2020) An atypical presentation of fulminant myocarditis secondary to COVID-19 infection. Cureus 12:e9179

73. Rubartelli P, Toselli A, Camerini A, Lupi G, Romeo M (2020) A patient with COVID-19 presenting multiple thrombi in the left ventricle. Acta Cardiol 1-3

74. Salamanca J, Díez-Villanueva P, Martínez P, Cecconi A, González de Marcos B, Reyes G et al (2020) COVID-19 "fulminant myocarditis" successfully treated with temporary mechanical circulatory support. JACC Cardiovasc Imaging 13(11):2457-2459

75. Sampaio PPN, Ferreira RM, Albuquerque FN, Colafranceschi AS, Almeida ACP, Nunes MAV et al (2020) Rescue venoarterial extracorporeal membrane oxygenation after cardiac arrest in COVID-19 myopericarditis: a case report. Cardiovasc Revasc Med S1553-8389(20)30590-X 
76. Tsao CW, Strom JB, Chang JD, Manning WJ (2020) COVID19-associated stress (Takotsubo) cardiomyopathy. Circ Cardiovasc Imaging 13:e011222

77. Vilaro J, Al-Ani M, Manjarres DG, Lascano JE, Cherabuddi K, Elgendy AY et al (2020) Severe COVID-19 after recent heart transplantation complicated by allograft dysfunction. JACC Case reports 2:1347-1350

78. Yuan WF, Tang X, Zhao XX (2020) An 'asymptomatic' driver with COVID-19: atypical suspected myocarditis by SARS-CoV-2. Cardiovasc Diagn Ther 10:242-243

79. Hakmi H, Sohail A, Brathwaite C, Ray B, Abrol S (2020) Cardiac tamponade in COVID-19 patients: management and outcomes. J Card Surg 35(11):3183-3190

80. Kazi DS, Martin LM, Litmanovich D, Pinto DS, Clerkin KJ, Zimetbaum PJ et al (2020) Case 18-2020: a 73-year-old man with hypoxemic respiratory failure and cardiac dysfunction. $\mathrm{N}$ Engl J Med 382:2354-2364

81. Khatri A, Wallach F (2020) Coronavirus disease 2019 (Covid19) presenting as purulent fulminant myopericarditis and cardiac tamponade: a case report and literature review. Heart Lung: J Crit Care 49(6):858-863

82. Radbel J, Narayanan N, Bhatt PJ (2020) Use of tocilizumab for COVID-19-induced cytokine release syndrome: a cautionary case report. Chest 158:e15-e19

83. Zeng JH, Liu YX, Yuan J, Wang FX, Wu WB, Li JX et al (2020) First case of COVID-19 complicated with fulminant myocarditis: a case report and insights. Infection 48:773-777

84. Hussain H, Fadel A, Alwaeli H, Guardiola V (2020) Coronavirus (COVID-19) Fulminant myopericarditis and acute respiratory distress syndrome (ARDS) in a middle-aged male patient. Cureus 12:e8808
85. Inciardi RM, Lupi L, Zaccone G, Italia L, Raffo M, Tomasoni D et al (2020) Cardiac Involvement in a patient with coronavirus disease 2019 (COVID-19). JAMA Cardiol 5:819-824

86. Fried JA, Ramasubbu K, Bhatt R, Topkara VK, Clerkin KJ, Horn $E$ et al (2020) The variety of cardiovascular presentations of COVID-19. Circulation 141:1930-1936

87. Kim IC, Kim JY, Kim HA, Han S (2020) COVID-19-related myocarditis in a 21-year-old female patient. Eur Heart J 41:1859

88. Hu H, Ma F, Wei X, Fang Y (2020) Coronavirus fulminant myocarditis saved with glucocorticoid and human immunoglobulin. Eur Heart J 42(2):206-206

89. Spano G, Fischer K, Maillat C, Vicario G, Huber AT, Gräni C (2020) Delayed isolated peri-myocarditis in a Covid-19 patient with respiratory symptoms but without lung involvement. Int J Cardiovasc Imaging 36:2279-2280

90. Juusela A, Nazir M, Gimovsky M (2020) Two cases of coronavirus 2019-related cardiomyopathy in pregnancy. Am J Obstet Gynecol MFM 2:100113

91. Irabien-Ortiz Á, Carreras-Mora J, Sionis A, Pàmies J, Montiel J, Tauron M (2020) Fulminant myocarditis due to COVID-19. Revista espanola de cardiologia (English ed) 73:503-504

92. Rassaf T, Totzeck M, Mahabadi AA, Hendgen-Cotta U, Korste S, Settelmeier S et al (2021) Ventricular assist device for a coronavirus disease 2019-affected heart. ESC heart failure 8:162-166

Publisher's Note Springer Nature remains neutral with regard to jurisdictional claims in published maps and institutional affiliations. 